\title{
Severe Hyponatremia Caused by Hypothalamic Adrenal Insufficiency
}

\author{
Takahisa Shibata, Toru OEdA and Yasushi SAIto
}

\begin{abstract}
A 60-year-old woman was admitted with severe hyponatremia. Basal values of adrenocorticotropic hormone (ACTH), thyroid hormone and cortisol were normal on admission. Impairment of water diuresis was observed by water loading test. Initially, we diagnosed her condition as the syndrome of inappropriate secretion of antidiuretic hormone (SIADH). By provocation test, we finally confirmed that the hyponatremia was caused by hypothalamic adrenal insufficiency. The basal values of ACTH and cortisol might not be sufficient to exclude the possibility of adrenal insufficiency. Therefore, it is necessary to evaluate adrenal function by provocation test or to re-evaluate it after recovery from hyponatremia.
\end{abstract}

(Internal Medicine 38: 426-432, 1999)

Key words: glucocorticoid, antidiuretic hormone, water loading test

\section{Introduction}

The syndrome of inappropriate antidiuretic hormone (SIADH) is a common cause of hyponatremia. The criteria for the diagnosis of SIADH was first described by Bartter and Schwartz (1). The new guideline for the diagnosis of SIADH recently reported by Saito (2), includes; 1) hyponatremia; serum sodium concentration lower than $135 \mathrm{mEq} / \mathrm{l}, 2$ ) low plasma osmolality; plasma osmolality lower than $270 \mathrm{mOsm} / \mathrm{kgH}_{2} \mathrm{O}$, 3 ) concentrated urine; urinary osmolality higher than 300 $\left.\mathrm{mOsm} / \mathrm{kgH}_{2} \mathrm{O}, 4\right)$ natriuresis; urinary sodium concentration higher than $20 \mathrm{mEq} / l, 5$ ) normal renal function; serum creatinine lower than $1.2 \mathrm{mg} / \mathrm{dl}, 6$ ) normal adrenal function; serum concentration of cortisol higher than $6 \mu \mathrm{g} / \mathrm{dl}$. Regarding the sixth criterion, adrenal insufficiency may be overlooked if the basal level of adrenocortical hormone is normal.

For editorial comment, see also p 382.

As the basal level of adrenocortical hormone was normal at the time of remarkable hyponatremia in this case, we initially excluded adrenal insufficiency in the diagnosis of SIADH. We finally diagnosed the disease as hyponatremia caused by hypothalamic adrenal insufficiency based on the results of provocation tests after the recovery of hyponatremia.

Here, we reported the clinical characteristics of the present case and how the plasma antidiuretic hormone (ADH) concentration changed with or without the administration of glucocorticoid.

\section{Case Report}

The case was a 60-year-old woman who had complained of general fatigue and appetite loss, and had noticed eczema on her trunk and extremities when she had eaten raw shiitake mushrooms as a private remedy in March 1997. She had not taken any medication inducing SIADH (e.g. psychopharmaceuticals, antiemetics, etc.). She was admitted because severe hyponatremia $(119 \mathrm{mEq} / l)$ was presented on April 15, 1997. She had suffered severe hemorrhage at her second delivery at the age of 27 . But her third delivery was normal. At the age of 52, she was diagnosed as post-transfusional chronic active type $\mathrm{C}$ hepatitis. On admission, her blood pressure was normal. She was very thin (body mass index 17), and her eyebrows and axillar hair were lost, but her pubic hair remained. There were no physical signs of edema or dehydration.

Laboratory data showed hyponatremia of $127 \mathrm{mEq} / \mathrm{l}$, but urinary sodium excretion was $150 \mathrm{mEq} /$ day (Table 1). Basal levels of pituitary anterior lobe and adrenocortical hormone were normal. In particular, adrenocorticotropic hormone (ACTH) and cortisol were normal, so we did not suspect her to have adrenal insufficiency. Plasma osmolality was low at 270 $\mathrm{mOsm} / \mathrm{kgH}_{2} \mathrm{O}$, while urinary osmolality was at a somewhat elevated concentration of $700 \mathrm{mOsm} / \mathrm{kgH}_{2} \mathrm{O}$. Plasma ADH concentration was high at $1.2 \mathrm{pg} / \mathrm{ml}$ compared to the low plasma osmolality. ACTH and ADH were measured by ACTH immunoradiometric assay and arginine vasopression (AVP) radioimmunoassay kits (Mitsubishi-Kagaku Co., Tokyo), respectively $(3,4)$. Cortisol, luteinizing hormone (LH) and follicle

From the Second Department of Internal Medicine, Chiba University School of Medicine, Chiba

Received for publication January 6, 1998; Accepted for publication November 9, 1998

Reprint requests should be addressed to Dr. Toru Oeda, Internal Medicine, Matsudo Municipal Hospital, 4005 Kamihongou, Matsudo $271-8511$ 
Hyponatremia in Adrenal Insufficiency

Table 1. Laboratory Data on Admission

\begin{tabular}{lrlr}
\hline $\begin{array}{l}\text { Peripheral blood exam } \\
\text { White blood cell }\end{array}$ & $3,000 / \mathrm{mm}^{3}$ & Creatinine & $0.44 \mathrm{mg} / \mathrm{dl}$ \\
Red blood cell & $379 \times 10^{4} / \mathrm{mm}^{3}$ & Uric acid & $6.9 \mathrm{mg} / \mathrm{dl}$ \\
Hemoglobin & $12.9 \mathrm{~g} / \mathrm{dl}$ & $\mathrm{Na}$ & $127 \mathrm{mEq} / l$ \\
Hematocrit & $35.0 \%$ & $\mathrm{~K}$ & $3.8 \mathrm{mEq} / l$ \\
Platelet & $15.6 \times 10^{4} / \mathrm{mm}^{3}$ & Urinalysis & $91 \mathrm{mEq} / l$ \\
Chemistry & & Urinary volume & $900 \mathrm{ml}$ \\
T-bilirubin & $0.4 \mathrm{mg} / \mathrm{dl}$ & Specific gravity & 1.018 \\
Aspertate aminotransferase & $34 \mathrm{IU} / l$ & Protein & $(-)$ \\
Alanine aminotransferase & $16 \mathrm{IU} / l$ & Glucose & $(-)$ \\
Alkaline phosphatase & $44 \mathrm{IU} / l$ & $\mathrm{Na}$ & $150 \mathrm{mEq} / \mathrm{day}$ \\
$\gamma$-glutamyltransferase & $14 \mathrm{IU} / l$ & $\mathrm{~K}$ & $18 \mathrm{mEq} / \mathrm{day}$ \\
Lactate dehydrogenase & $420 \mathrm{IU} / l$ & $\mathrm{Cl}$ & $159 \mathrm{mEq} / \mathrm{day}$ \\
Total protein & $6.8 \mathrm{~g} / \mathrm{dl}$ & & \\
Blood urea nitrogen & $11 \mathrm{mg} / \mathrm{dl}$ & & \\
\hline
\end{tabular}

stimulating hormone (FSH) were measured by cortisol radioimmunoassay, LH immunoradiometric assay and FSH immunoradiometric assay kits (Daiichi Radioisotope Lab., Tokyo), respectively $(5,6)$ (Table 2).

On April 28, a water loading test was performed. Serum sodium concentration at $8 \mathrm{AM}$ was $136 \mathrm{mEq} / \mathrm{l}$. It showed that urinary osmolality was not diluted lower than the plasma osmolality, and urinary volume in 4 hours was only $31 \%$ of water loading volume, indicating that her water diuresis was impaired. In view of these data, we diagnosed her as SIADH (Fig. 1A). At 6 PM, she complained of nausea, and her serum sodium concentration was low at $128 \mathrm{mEq} / \mathrm{l}$. We treated her with hypertonic saline with furosemide but her nausea continued until the next morning.

After admission, hyponatremia improved within several days by water restriction of less than $500 \mathrm{ml} /$ day. We performed a pituitary anterior lobe provocation test on April 23, because of her past history of severe hemorrhage in her second delivery but then a normal third delivery. Growth hormone (GH), LH, $\mathrm{FSH}$, and prolactin (PRL) showed no response and thyroid stimulating hormone (TSH) showed a normal response (Fig. $2 \mathrm{~A}-2 \mathrm{C}$ ). Brain magnetic resonance imaging showed partial empty sella, and as far as we searched, no organic disease was shown in the hypothalamus.

ACTH and cortisol showed a delayed response by the administration of corticotropin releasing hormone (Fig. 2D), and the insulin tolerance test showed no response for ACTH and cortisol (Fig. 2E). Although no symptom or sign of hypoglycemia was shown after the administration of insulin, her blood glucose dropped from $70 \mathrm{mg} / \mathrm{dl}$ to $31 \mathrm{mg} / \mathrm{dl} 30$ minutes after the administration of insulin. Further cortisol showed a normal response by the rapid administration of ACTH (Fig. 2F). Urinary 17-hydroxycorticoids (17-OHCS) and 17-ketosteroids (17$\mathrm{KS}$ ) were low at $0.97 \mathrm{mg} /$ day (normal range; $1.33-5.39$ ) and $0.83 \mathrm{mg} /$ day (normal range; $1.98-7.39$ ), respectively. But these data were measured several days after than the measurement of basal ACTH and cortisol, that was, after improvement of
Table 2. Endocrinological Data
Adrenocorticotropin

Cortisol

Plasma aldosterone concentration

Plasma renin activity

Thyroid stimulating hormone

Free 3, 5, 3'-Triiodothyronine

Free Thyroxine

Reverse 3, 5, 3'-Triiodothyronine

Anti-thyroglobulin antibody

Anti-thyroid peroxydase antibody

Growth hormone

Prolactin

Luteinizing hormone

Follicular stimulating hormone

Antidiuretic hormone

Plasma osmolality

Urine osmolality
$37.4 \mathrm{pg} / \mathrm{ml}(10.0-60.0)$

$12.1 \mu \mathrm{g} / \mathrm{dl}(5.0-20.0)$

$162 \mathrm{pg} / \mathrm{ml}(10.0-180.0)$

$<0.15 \mathrm{ng} / \mathrm{ml} / \mathrm{h}(0.2-2.7)$

$1.71 \mu \mathrm{U} / \mathrm{ml}(0.5-5.0)$

$2.1 \mathrm{pg} / \mathrm{ml}(1.45-4.65)$

$0.7 \mathrm{ng} / \mathrm{dl}(0.8-2.2)$

$167 \mathrm{pg} / \mathrm{ml}(190-375)$

$<0.3 \mathrm{U} / \mathrm{ml}(<0.3)$

$<0.3 \mathrm{U} / \mathrm{ml}(<0.3)$

$0.16 \mathrm{ng} / \mathrm{ml}(0.0-5.0)$

$6.58 \mathrm{ng} / \mathrm{ml}(0.0-20.0)$

$1.9 \mathrm{mIU} / \mathrm{ml}(8.7-38.0)$

$8.9 \mathrm{mIU} / \mathrm{ml}(26.2-113.3)$

$1.2 \mathrm{pg} / \mathrm{ml}(0.3-3.5)$

$270 \mathrm{mOsm} / \mathrm{kgH}_{2} \mathrm{O}(276-292)$

$700 \mathrm{mOsm} / \mathrm{kgH}_{2} \mathrm{O}$
The normal ranges were obtained from the Department of Clinical Laboratory, Chiba Medical School Hospital.

hyponatremia. Finally, she was diagnosed as hypothalamic adrenal insufficiency.

For these results, we repeated the water loading test on May 16 , after the administration of $40 \mathrm{mg}$ hydrocortisone in order to clarify the participation of glucocorticoid in the impairment of water diuresis (Fig. 1D). The serum sodium concentration at $8 \mathrm{AM}$ was $132 \mathrm{mEq} / l$. Urinary volume in 4 hours was $83 \%$ of water loading volume, and urinary osmolality was diluted lower than plasma osmolality (Fig. 1D and 1E). Free water clearance values were all negative without hydrocortisone administration, but with hydrocortisone we could confirm that they turned positive (Fig. 1C and 1F).

She was discharged on May 20,1997, and began to take 10 $\mathrm{mg}$ of hydrocortisone per day. After this treatment for 1 week, 
A

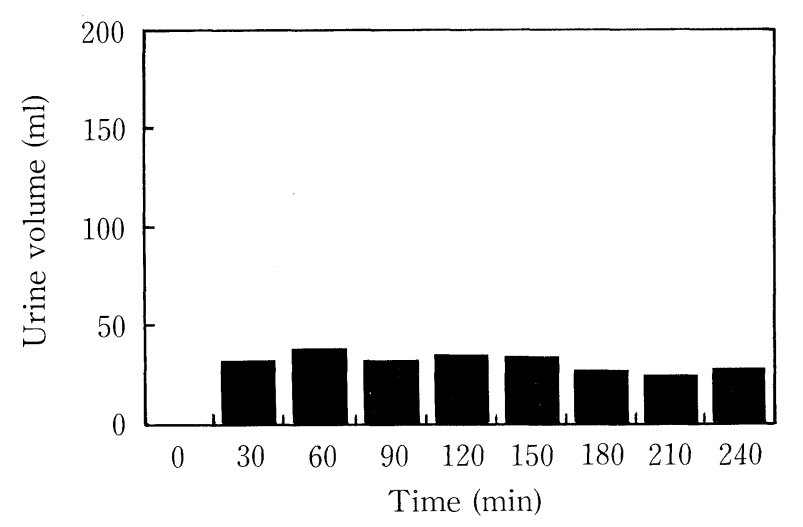

B

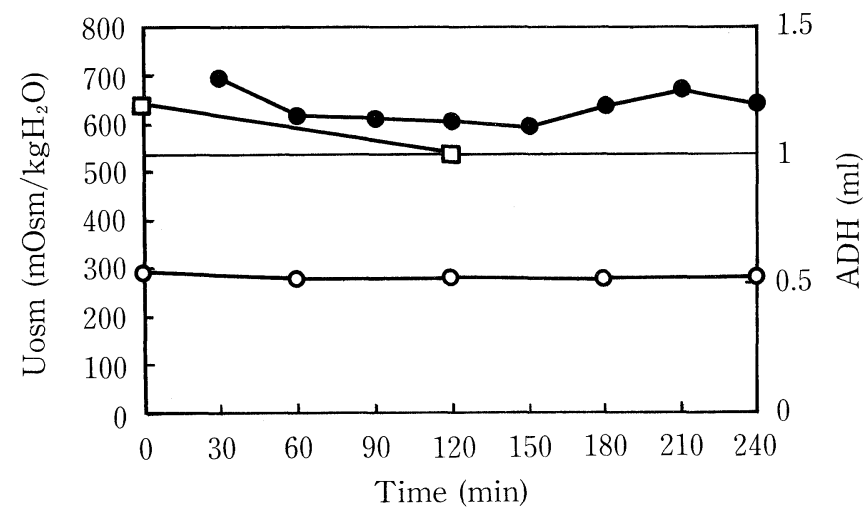

C

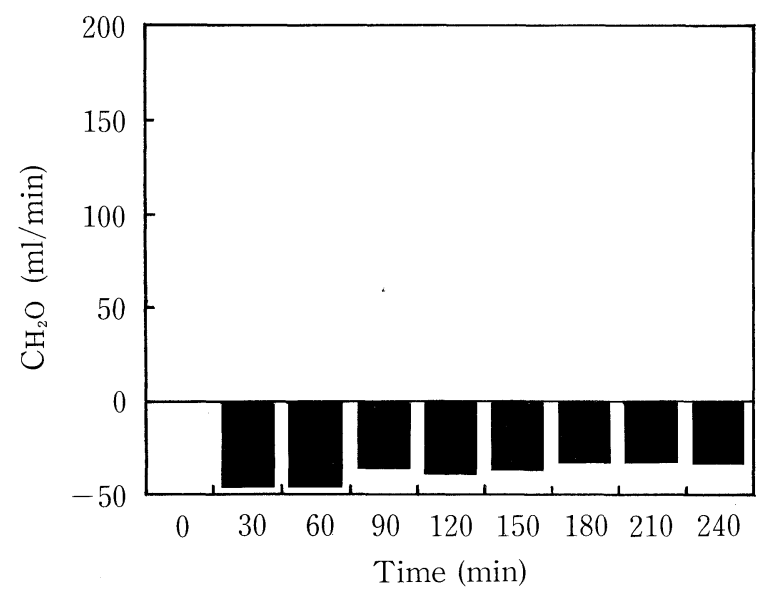

D

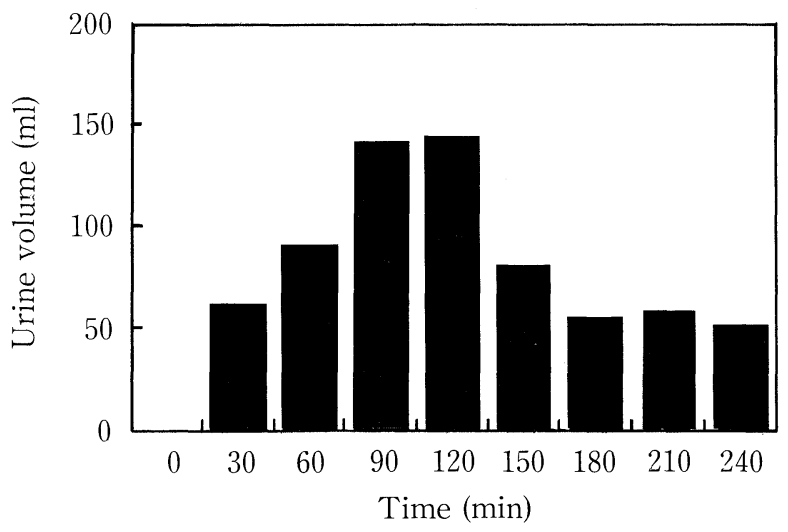

E

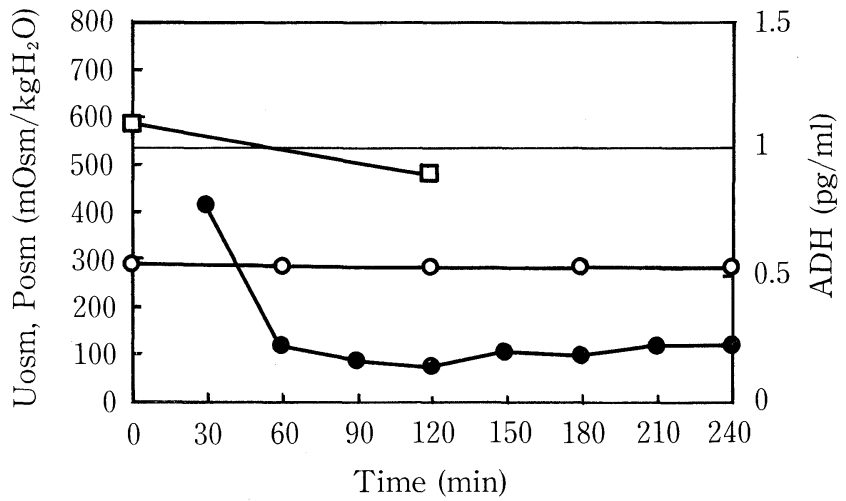

F

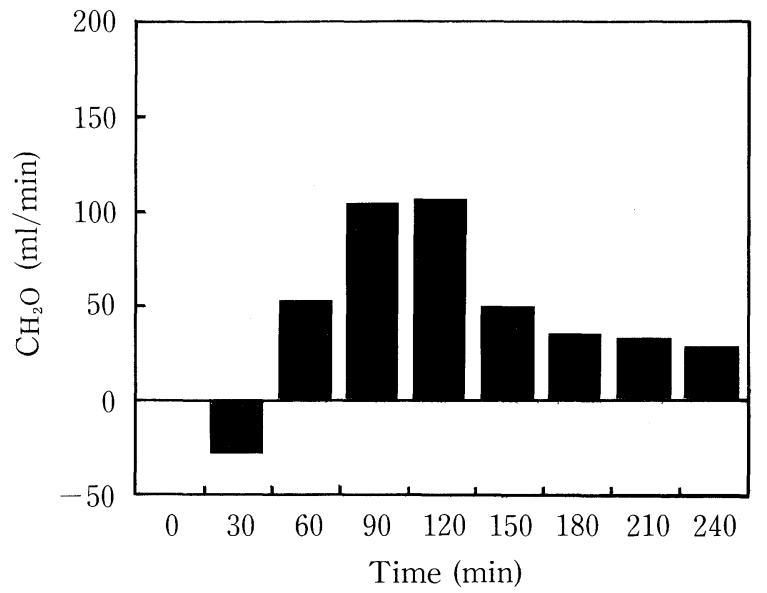

Figure 1. Water loading test with and without glucocorticoid. A: water loading test without glucocorticoid on April 28. B: water loading test with glucocorticoid. At 8 PM on May 15 and at 7:30 AM on May 16, 20 mg of hydrocortisone was administered orally. Water $(20 \mathrm{ml} / \mathrm{kg}$ weight $)$ was loaded orally within 20 minutes at 8 AM A and D: urinary volume in 4 hours. B and E: urinary osmolality ( $\bigcirc$ ), plasma osmolality $(\bigcirc)$ and ADH ( $\square$ ). C and F: free water clearance. 
Hyponatremia in Adrenal Insufficiency

A

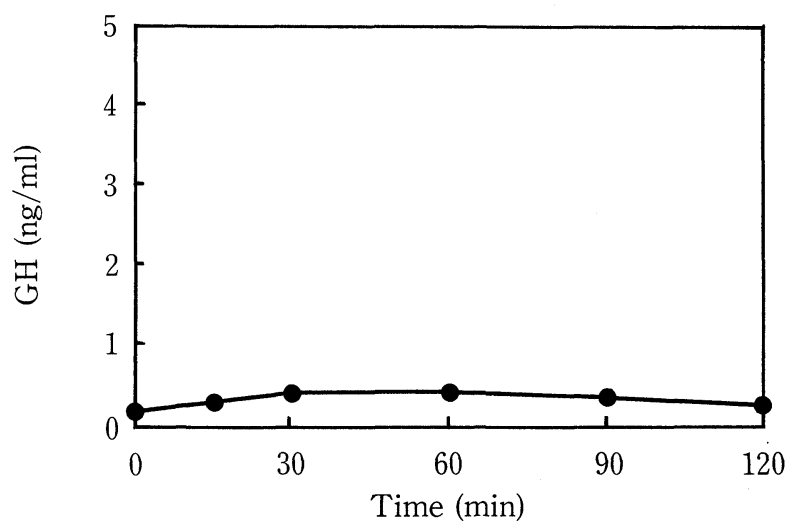

$\mathrm{B}$

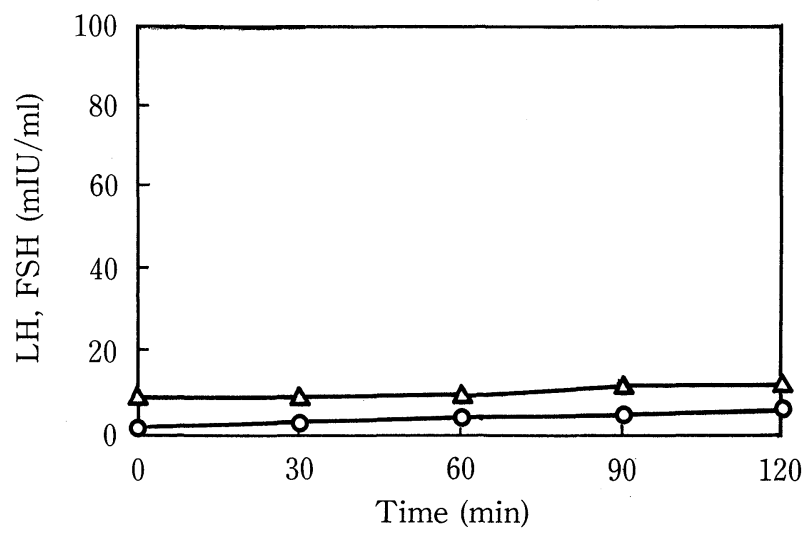

$\mathrm{C}$

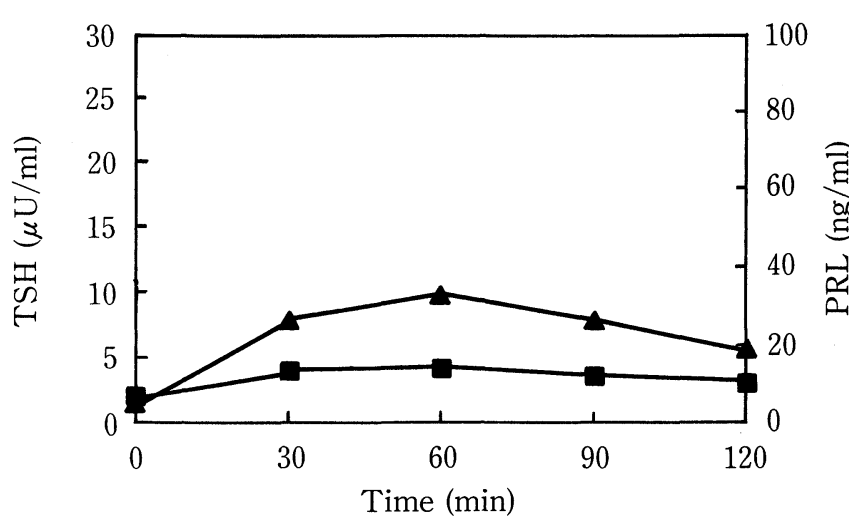

$\mathrm{D}$

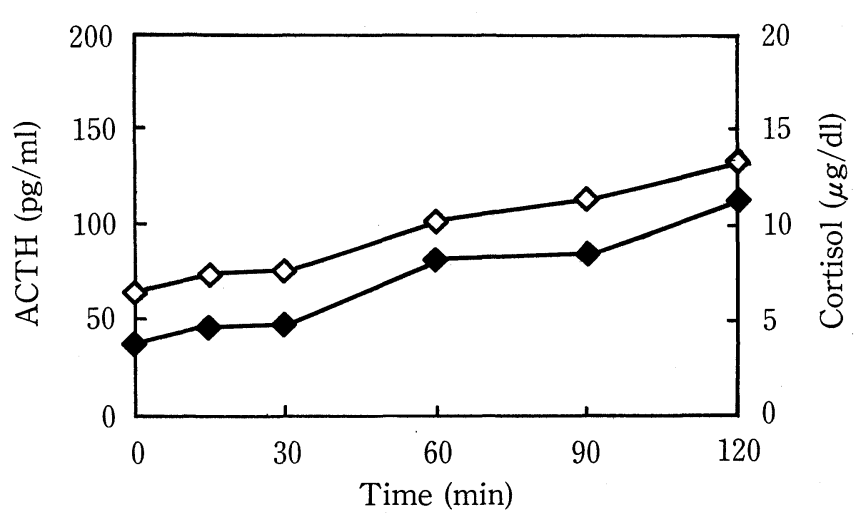

$\mathrm{E}$

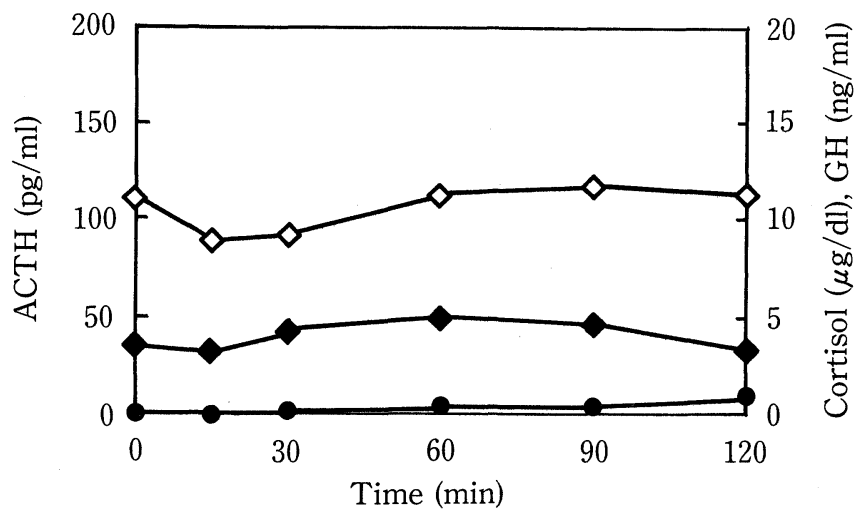

$\mathrm{F}$

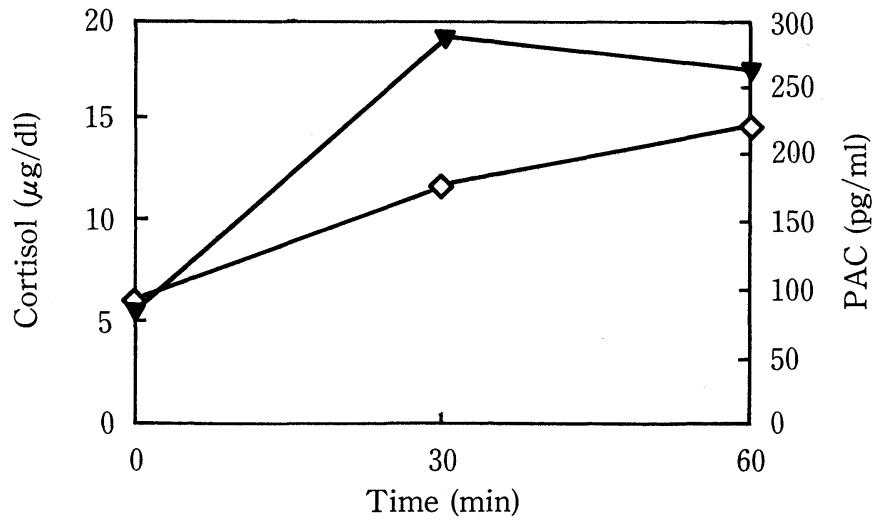

Figure 2. Hypothalamic-pituitary-adrenal function test. A: GRH provocation test. GRH ( $80 \mu \mathrm{g}$, i.v.) was administered. GH (O). B: LHRH provocation test. LHRH (0.1 mg, i.v.) was administered. LH $(\triangle)$ and FSH $(\bigcirc)$. C: TRH provocation test. TRH $(500 \mu \mathrm{g}$, i.v.) was administered. TSH ( $\triangle$ ) and Prolactin (PRL); ( $\square$ ). D: CRH provocation test. CRH (80 $\mu \mathrm{g}$, i.v.) was administered. ACTH $(\diamond)$ and cortisol $(\diamond)$. E: insulin tolerance test. Regular insulin (0.05 U/kg weight) was administered. ACTH, cortisol and GH (O). F: rapid ACTH provocation test. ACTH $(0.25 \mathrm{mg}$, i.v.) was administered. Plasma aldosterone concentration (PAC; $\nabla$ ) and cortisol. The test was done at $8 \mathrm{AM}$. 
A

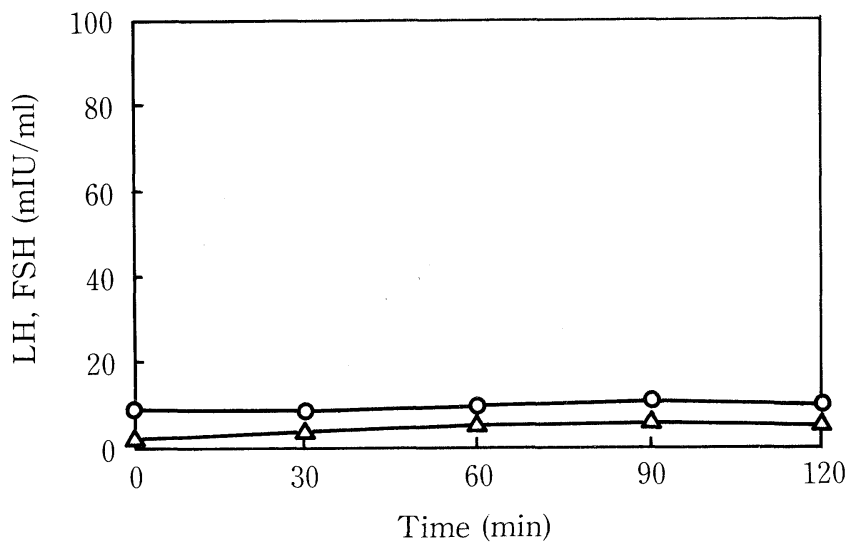

$\mathrm{B}$

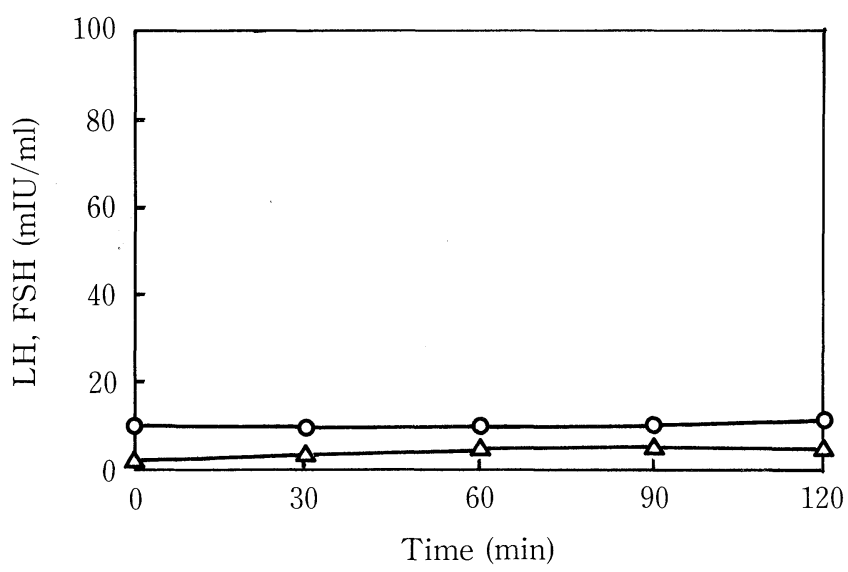

C

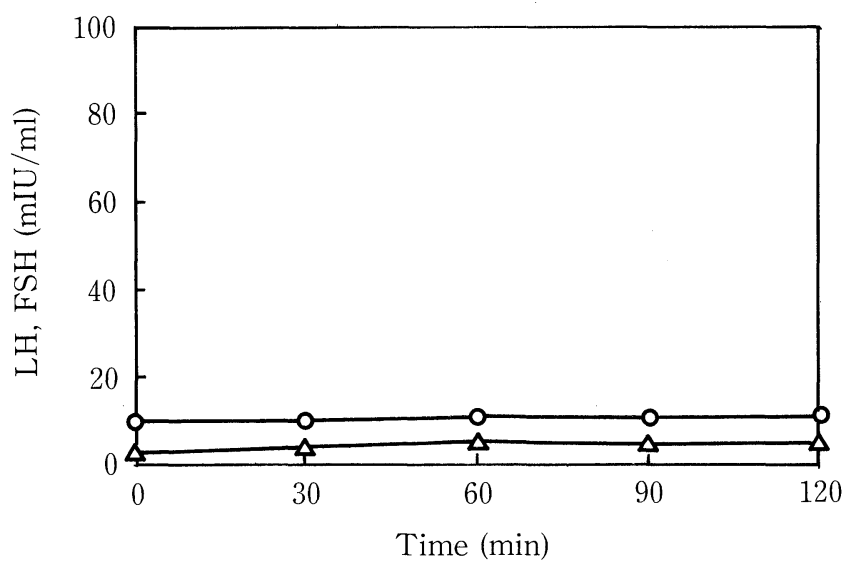

Figure 3. LHRH provocation test daily for five days. The daily administration of $10 \mathrm{mg}$ hydrocortisone for 1 week was followed by the administration of LHRH (0.1 mg, i.v.) daily for five days. A C: $\mathbf{L H}(\triangle)$ and FSH $(\bigcirc)$. A, first day; B, third day; and $C$, fifth day.

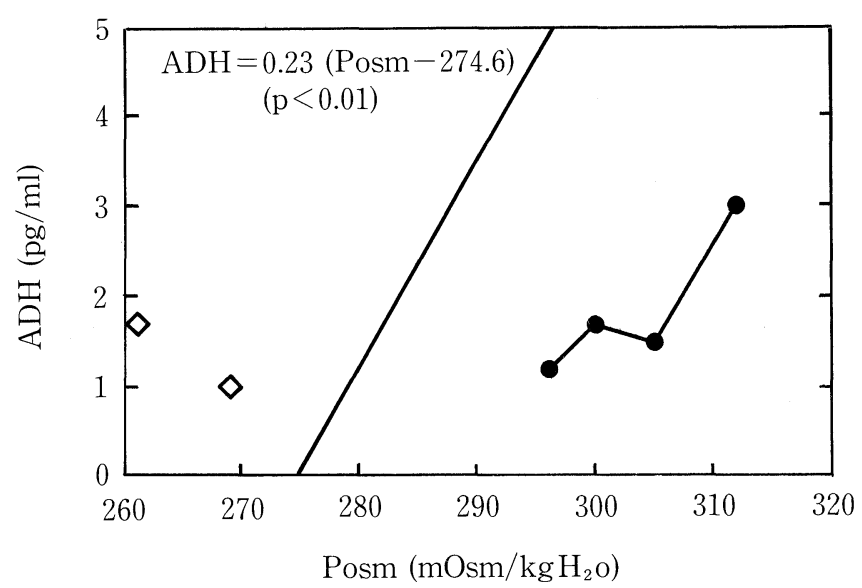

Figure 4. Plasma osmolality in relation to plasma ADH concentration in this case. The diamonds represent the initial values on April 11 and April 15 in this case. The closed circles represent data during the $5 \%$ hypertonic saline infusion test on October 27 after replacement of glucocorticoid. The straight line represents the regression line $(20)$.

LHRH provocation tests were done for five consecutive days. LH and FSH were all negative (Fig. 3).

We did not perform the hypertonic saline infusion test before treatment due to the potential risk considering her severe hyponatremia. Two points measured before the treatment were plotted in Fig. 4. After the administration of $10 \mathrm{mg}$ hydrocortisone, the 5\% hypertonic saline infusion test was performed on October 27 in order to estimate the relationship between the ADH threshold and plasma osmolality (Fig. 4). We confirmed that the osmotic threshold of ADH secretion was increased by replacement of glucocorticoid.

\section{Discussion}

Because this case fulfilled all of the Saito's new guideline criteria (2) from the first to the fifth items and the basal serum values of adrenal steroids were normal, we initially diagnosed this case as SIADH. By the pituitary anterior lobe provocation test, however, ACTH and cortisol showed a delayed response and the other pituitary anterior lobe hormones showed no response except for TSH. Further, by the insulin tolerance test, ACTH and cortisol showed no response. Basal urinary 17OHCS and 17-KS excretions were low. The water loading test after hydrocortisone therapy revealed improvement of water diuresis. Thus, we were finally able to confirm that the hyponatremia was caused by hypothalamic adrenal insufficiency. We only found one report in the literature regarding basal adrenal levels within the normal range in adrenal insufficiency (7). Hyponatremia is one of the features in patients with hypopituitarism. These patients have various complications, such as anorexia, nausea and vomiting. In severe cases, serious lifethreatening neurological disorders such as convulsion and coma 


\section{Hyponatremia in Adrenal Insufficiency}

might occur. The reported case was not primary adrenal insufficiency but secondary (pituitary), and the present case was tertiary (hypothalamic). In the case of secondary or tertiary adrenal insufficiency, the adrenal gland might be stimulated by various endogenous stimuli under severe stress and secrete some amount of adrenal hormone as in normal adrenal function, but it is not sufficient to overcome stress.

A simple differential method is Oleesky's test. Oleesky reported in 1953 that the impairment of water diuresis in patients with adrenal insufficiency is improved by acute administration of glucocorticoid (8). In fact, as shown in Fig. 1A and 1D, this approach was also successful in our case.

Dingman and Despointes (9) first speculated that glucocorticoid enhances water diuresis in normal subjects and in patients with Addison's disease by inhibiting the hypothalamic control of ADH release, rather than by competition with ADH at the renal tubular level. Further, the administration of glucocorticoid was reported to increase the osmotic threshold of ADH secretion and to suppress its secretion in normal subjects (10). There have been reports of several cases of primary or secondary adrenal insufficiency being caused hyponatremia by the inappropriate secretion of $\mathrm{ADH}(11-16)$. The plasma ADH level 2 hours after water loading has been reported to be suppressed to less than $1.0 \mathrm{pg} / \mathrm{ml}$ in healthy subjects and the plasma ADH level before the use of hydrocortisone in the present case was $1.0 \mathrm{pg} / \mathrm{ml}$, indicating that ADH may have been secreted inappropriately (Fig. 1B). The concentration of ADH was then suppressed to $0.7 \mathrm{pg} / \mathrm{ml}$ with hydrocortisone, improving the secretion of ADH by glucocorticoid (Fig. 1E).

In the present case, we did not perform the hypertonic saline infusion test before treatment due to the potential risk considering her severe hyponatremia. Several points measured before the treatment were plotted in Fig. 4. All of them were in left side of normal straight regression line. After the administration of $10 \mathrm{mg}$ hydrocortisone, the 5\% hypertonic saline infusion test was performed in order to estimate the relationship between the ADH threshold and plasma osmolality (Fig. 4). The plot line was not in left side of normal straight regression line, indicating that the osmotic threshold of ADH secretion in adrenal insufficiency might be decreased in relation to plasma osmolality, and ADH secretion was increased inappropriately. The osmotic threshold of ADH secretion was increased by replacement of glucocorticoid. In short, the pathogenesis of hyponatremia in adrenal insufficiency is partially the same as that in SIADH.

In the present case, considering her pituitary-adrenal dysfunction, hyponatremia and inappropriate $\mathrm{ADH}$ secretion were severe. Recently it was reported that interleukin (IL)- $1 \beta$ stimulates the secretion of corticotropin releasing hormone, ACTH and corticosteroid (17), and induces an increase in the level of $\mathrm{ADH}$ in rats (18). The present case experienced eczema on the trunk and extremities when she had eaten raw shiitake mushrooms as a private remedy. We consider that such an immunological pathogenesis can participate in the exacerbation of hyponatremia.

All basal values of thyroid function measured several times were within normal limits. In the thyrotropin-releasing hormone (TRH) provocation test, TSH showed a normal response (Fig. 2C). Adrenal insufficiency is known to influence thyroid function. After the administration of $10 \mathrm{mg}$ hydrocortisone per day for 1 week, the TRH provocation test was done again (data not shown). TSH showed a normal response. Hyponatremia induced by hypothyroidism is known to be caused by the impairment of water diuresis, urinary excretion of sodium and the elevation of urinary osmolality. However, the inappropriate secretion of ADH has been reported not to be involved in this pathogenesis (19). Hypothyroidism may not have been influential in this case.

LH and FSH showed no response to daily LHRH provocation tests for five days (Fig. 3). We consider that these responses indicate that hypothalamic hypogonadism for a long time might have seemed as if it was pituitary disorder. Furthermore, we could not distinguish between somatopause and hyposomatonism, but, the lack of GH response also could be caused by hypothalamic hyposomatonism.

In conclusion, in cases of inappropriate secretion of $\mathrm{ADH}$, we consider that one should be cautious in estimating the pituitary-adrenal function, and that provocation tests for evaluating pituitary-adrenal function are necessary.

\section{References}

1) Bartter FC, Schwartz WB. The syndrome of inappropriate secretion of antidiuretic hormone. Am J Med 42: 790-806, 1967.

2) Saito T. SIADH and other hyponatremic disorders: diagnosis and therapeutic problems. Nippon Jinzo Gakkai Shi 38: 429-434, 1996.

3) Tozawa F, Suda T, Demura H. Determination of ACTH levels in human plasma using an ACTH-II IRMA kit "MitsubishiYuka". Horumon To Rinsho 39: 1235-1239, 1991.

4) Yoshida S, Yamada K, Kimura T, et al. Measurement of arginine vasopressin in plasma using AVP-RIA Kit. Horumon To Rinsho 35: 515-519, 1987.

5) Niinomi M, Ando M, Toya Y, Minanikawa Y, Matsui N. Studies on solidphase radioimmunoassay of cortisol, "SPAC cortisol kit". Horumon To Rinsho 28: 321-327, 1980.

6) Aono T, Matsumoto $S$, Kumamoto E, et al. Multi centric clinical studies on immunoradiometric assay (SPAC-S LH, SPAC-S FSH) for measurement of serum LH and FSH using the pituitary gonadotropin/standards. Horumon To Rinsho 36: 1087-1097, 1988.

7) Sakurai A, Yamada T, Hashizume K. A case of initially undiagnosed hypoadrenalism presenting inappropriate secretion of anti-diuretic hormone. Endocr J 42: 811-815, 1995.

8) Oleesky S. A specific water diuresis test for adrenocortical insufficiency. Lancet 1: 769-770, 1953.

9) Dingman JF, Despointes RH. Adrenal steroid inhibition of vasopressin release from the neurohypophysis of normal subjects and patients with Addison's disease. J Clin Invest 39: 1851-1863, 1960.

10) Moses AM, Streeten DH. Differentiation of polyuric states by measurement of responses to changes in plasma osmolality induced by hypertonic saline infusions. Am J Med 42: 368-377, 1967.

11) Ahmed AB, George BC, Gonzalez-Auvert $C$, Dingman JF. Increased plasma arginine vasopressin in clinical adrenocortical insufficiency and its inhibition by glucosteroids. J Clin Invest 46: 111-123, 1967.

12) Boykin J, DeTorrente A, Erickson A, Robertson G, Schrier RW. Role of plasma vasopressin in impaired water excretion of glucocorticoid deficiency. J Clin Invest 62: 738-744, 1978.

13) Okuno $S$, Inaba $M$, Nishizawa $Y$, Miki T, Inoue $Y$, Morii H. A case of hyponatremia in panhypopituitarism caused by the primary empty sella 


\section{SHibata et al}

syndrome. Endocrinol Jpn 34: 299-307, 1987.

14) Oelkers W. Hyponatremia and inappropriate secretion of vasopressin (antidiuretic hormone) in patients with hypopituitarism. N Engl J Med 321: 492-496, 1989.

15) Ishikawa S, Fujisawa G, Tsuboi Y, Okada K, Kuzuya T, Saito T. Role of antidiuretic hormone in hyponatremia in patients with isolated adrenocorticotropic hormone deficiency. Endocrinol Jpn 38: 325-330, 1991.

16) Kamoi $K$, Tamura T, Tanaka $K$, Ishibashi $M$, Yamaji T. Hyponatremia and osmoregulation of thirst and vasopressin secretion in patients with adrenal insufficiency. J Clin Endocrinol Metab 77: 1584-1588, 1993.
17) Woloski BM, Smith EM, Meyer WJ, Fuller GM, Blalock JE. Corticotropin-releasing activity of monokines. Science 230: 1035-1037, 1985.

18) Naito Y, Fukata J, Shindo K, et al. Effects of interleukins on plasma arginine vasopressin and oxytocin levels in conscious, freely moving rats. Biochem Biophys Res Comm 174: 1189-1195, 1991.

19) Koide $Y$, Oda K, Shimizu K, et al. Hyponatremia without inappropriate secretion of vasopressin in a case of myxedema coma. Endocrinol Jpn 29: 363-368, 1982.

20) Yoshida S. Disorders of the posterior pituitary. Nippon Naika Gakkai Zasshi 77: 1373-1377, 1988. 